\title{
Creating and Sustaining a Maintenance Strategy: A Practical Guide
}

\author{
Kenneth Robson ${ }^{1}$, Robert Trimble ${ }^{2} \&$ John MacIntyre ${ }^{2}$ \\ ${ }^{1}$ Faculty of Applied Sciences, Department of Computing, Engineering and Technology, University of Sunderland, St \\ Peters Campus, David Goldman Building, Sunderland, SR6 0DD, United Kingdom \\ ${ }^{2}$ Faculty of Applied Sciences, University of Sunderland, St Peters Campus, David Goldman Building, Sunderland, \\ SR6 0DD, United Kingdom
}

Correspondence: Ken Robson, Faculty of Applied Sciences, Department of Computing, Engineering and Technology, University of Sunderland, St Peters Campus, David Goldman Building, Sunderland, SR6 0DD, United Kingdom. Tel: 44-515-2881. E-mail: ken.robson@sunderland.ac.uk

Received: March 19, 2013

Accepted: April 14, 2013

Online Published: April 22, 2013

doi:10.5430/jbar.v2n1p77

URL: http://dx.doi.org/10.5430/jbar.v2n1p77

\begin{abstract}
Manufacturing companies should create maintenance strategy and link it to the manufacturing and business goals but recent research in the North East of England suggested that few companies do this. It is unclear why this inertia existed but it could have been due to the complexity and variety of the advice on offer in relation to the formulation and implementation of strategy. The purpose of this paper was to provide a simple generic guide or roadmap for practitioners to follow. It began by highlighting the importance and benefits of a maintenance strategy and then considered literature appropriate to the topic. A key point arising from this review was that the three elements; process, content, context, need to be considered over the lifecycle of a strategy. Moreover, most strategic models converged to simple sequential models affording a generic functional process to be developed. This involved the integration of the "corporate hard systems" model and the "Plan, do, check, act, cycle", forming a suitable maintenance strategy process. Accordingly, further guidance on policy assured the right "content". The paper concluded with a short questionnaire used to audit the effect of "contextual factors" on maintenance strategy. The result was a comprehensive guide on how to formulate and implement maintenance strategy.
\end{abstract}

Keywords: Maintenance strategy, Audit, Contextual factors, Questionnaire

\section{Introduction}

The need to improve manufacturing operations in the UK is without question. Global competition is intense and this has forced several UK manufacturing companies to transfer operations to low-cost economies. It is therefore imperative that the remaining manufacturing facilities continuously improve and become as efficient and effective as possible. The primary mechanism in business to steer such actions is strategy and this should be developed, implemented and linked across corporate, business and functional levels (Skinner, 1969, Pinjala et al., 2004). When manufacturing performance is considered, equipment maintenance has a key influence on safety, cost, customer service, and quality. Research by Robson (2010) found that maintenance organizations in the North East of England were not creating maintenance strategies and linking them to manufacturing and business goals. However, this may not be an issue unique to the UK because similar concerns were raised in Sweden by the research of Jonsson (1997).

It is not clear why managers choose not to create a maintenance strategy (Note 1) but it could be that they "do not know how". The plethora of strategic models and frameworks certainly makes it difficult, because there is no clear pathway for practitioners to follow. This paper addresses the problem by firstly reviewing the literature in respect to strategy and from this, developing a pragmatic approach to the formulation and implementation of a maintenance strategy. The structure of the paper is as follows: Section 2 considers the benefits of creating a maintenance strategy and why it is important to do so; Section 3 presents a short review of the literature covering both corporate and maintenance strategy; Section 4 proffers a practical approach to developing a maintenance strategy; Section 5 explains how a maintenance strategy can be audited and finally; Sections 6 provides a set of conclusions. 


\section{Why create a maintenance strategy?}

Maintenance strategies are important because they can bring significant benefits to manufacturing organizations. The interdependence between manufacturing operations and equipment maintenance means that if a suitable maintenance strategy is deployed this should lead to improved machine reliability and availability. A maintenance strategy also ensures that scarce and expensive resources i.e. maintenance labor and materials are efficiently and effectively used. In the UK, most manufacturing companies expend between 4-6\% of their annual turnover on maintenance (Willmott, 1994). The alternative to a maintenance strategy is poor and ineffective equipment maintenance, which will detrimentally affect all areas of manufacturing operations. Improving the reliability of machines also aligns well with the concepts of Lean Manufacturing, because reliable machines mean repeatable and predictable processes which in turn, reduce the waste due to overproduction and unplanned stoppages (Slack et al., 2007). The completion of customer orders in full and on time becomes more likely as product defects caused by equipment failures diminish. From a maintenance organizational perspective, a holistic maintenance strategy sets out a sustainable vision for the future with clear policies for equipment maintenance and staff. This covers a wide gamut of topics e.g. objectives, goals, appropriate machine maintenance tactics, performance measures, training, staff development, succession planning etc. The generation of a documented strategy with agreed plans, also promotes the reputation of the maintenance function within the plant hierarchy, raising its profile and strategic status. In this situation, the maintenance function is no longer a "necessary evil" but rather a function that is positively contributing to the business and measuring its performance and progress against agreed targets.

\section{Literature review}

The term strategy originated from the military and came from the Greek word "strategia" meaning "generalship" or "The General's Way". As the field of strategic management and corporate strategy developed, much has been written about strategy, but a single definition remains elusive. One simple but succinct definition for strategy is provided by Hart (1967) when he describes it as 'The art of distributing and applying military means to fulfill the ends of policy'. However, over the years there has been a major debate about how strategy is formed and there are many schools of thought on this topic (Mintzberg et al., 1998). The range of views can be represented along a continuum between determinism and voluntarism (Genus, 2000). At one end of the continuum, authors believe strategy is determined deliberately, whereas at the other end of the scale authors hold a serendipitous view and believe everything happens by chance. The dominant view in corporate strategy literature is the former, that strategy is planned and determined deliberately and this is known as the 'rational planning paradigm' (Ackoff, 1981, Ansoff, 1988, Johnson and Scholes, 1993). Here, strategy (or how to compete) is formulated at a corporate level and then cascaded down through the organization via plans, goals and objectives (Certo, 1991, Johnson and Scholes, 1993, Ackoff, 1981). This is a "top down" approach. These concepts are tempered by the work of Mintzberg and Waters (1985) who suggest that strategies can also emerge "bottom up". A mixture of "top down" and "bottom up" approaches are often used.

Another important concept to absorb is that strategy has three dimensions i.e. "process", "content" (Voss, 1992) and "context" (Pettigrew, 1987). The first element is that strategy needs to follow a "process" i.e. a sequence of predefined prescriptive steps or stages. The second element is "content" or what the strategy contains, the areas to be focused on, the objectives set e.g. improving quality, delivery, speed, flexibility, cost (QDFSC) (Slack et al., 2004). The third element of strategy is "context". This is the environment strategy exists within. All strategists need to be aware that "internal" and "external" "contextual" factors can impact strategy. In particular, internal factors such as culture, politics and history (Pettigrew, 1987) have been shown to adversely affect the strategy process in manufacturing plants (Barnes, 2002).

Focusing on the functional level of maintenance, there were many strategic frameworks and models to consider. The first attempt of note was the 'EUT maintenance model' (Eindhoven University of Technology) (Geraerds, 1990). This was further developed by Coetzee (1997) and adapted by Tsang et al (1999 p. 694) into a 'general maintenance model'. A similar framework was proposed by Kelly (1997b) called the 'business centered approach for the formulation of maintenance strategy'. These frameworks although comprehensive were quite difficult to follow because they tried to integrate both "process" and "content" in one model. For example, the Tsang et al. (1999 p. 694) model consisted of two cycles. The outer process described the 'Maintenance Management' cycle used to establish the policies, objectives, plans, and performance and included feedback mechanisms for performance. Whereas, the inner "Maintenance" cycle defined the operational level i.e. the implementation of the policy decisions or as Tsang (1998) described it 'The combination of all technical and administrative actions, including supervision actions'. More useable strategic models were generated when the "process" and "content" were separated out e.g. in the models proposed by Kelly (1997a p 2) and (Tsang, 1998 p.91). These "holistic maintenance models" were essentially 
variants of corporate and manufacturing models, so to develop a generic functional strategy process the "corporate hard systems model" (Bignell et al., 1984a) was used in Section 4.

\section{How to create a maintenance strategy}

\subsection{Process}

Maintenance managers should use a strategic process when making significant changes or improvements. This is particularly the case when the maintenance function is required to contribute to manufacturing and business goals and they need to develop their own strategies and plans to meet the overall objectives. In this situation, a strategic process is best because it provides a structure and guides the steps of the would-be strategist.

As mentioned earlier in Section 3 there are many possible models and frameworks but the simplest and probably the most popular generic framework is the "corporate hard systems" model (Bignell et al., 1984b). This asks three basic questions; where are we now? (the "current state") where do we want to be? (the "future state") and how can we get there? (the strategy or plan). The first step in the process establishes the future state. This should be defined with specific, measurable, achievable, realistic and timely objectives (SMART) (Cross and Lynch, 1989). These objectives should be coherently aligned to the manufacturing and business goals (Jonsson, 1997). Once the "future state" objectives are established, the "current state" is measured in relation to these objectives. So for example, if the maintenance objective was to "reduce the cost of store stock holdings by $\mathrm{X} \%$ in a certain time period" then an assessment and analysis of the stock, costs and quantities would need to be made. The next step would be to consider the strategy or, in this case, how to make the savings and then from this a plan can be formed. The stage of developing "potential solutions" to the problems is probably the most difficult part of the process. This is because it entails identifying the gap between the "current" and "future" state and establishing ways of closing this gap. After creating the strategy, the next stage is to execute the plan. A model such as the Plan-Do-Check-Act cycle (PDCA) or similar should be used to control measure and manage the process. This is important because the 'tracking the performance of maintenance [is]... a key management issue' (Tsang et al., 1999). Bringing the formulation and execution phases together the whole process can represented in a single diagram as shown in figure 1 . This adapted process forms the basis for developing any functional strategy.

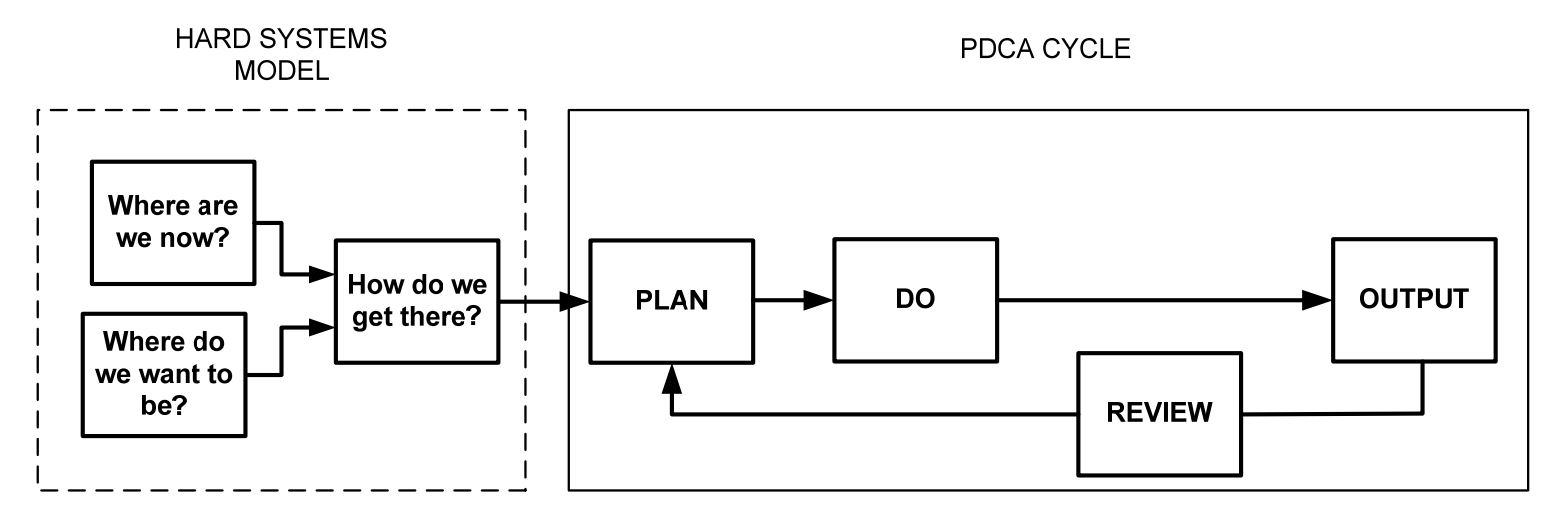

Figure 1. A process for formulating and implementing functional strategy Adapted by: Robson (2010) using Bignell et al. (1984b) and (Slack et al., 2004)

\subsection{Content}

It is important that three levels of work are considered when developing the "content" for maintenance strategy. The conceptual diagram in figure 2 shows the three possible work areas. The first area relates to the policy decisions concerning the day-to-day running of the business i.e. the deployment of systems, people, and technologies in the operation and maintenance of the plant. The second consideration should be the management of continuous improvement activities and the direction they should take. Continuous improvement is a highly important activity and is a key element of a maintenance strategy (Cholasuke et al., $2004 \mathrm{p} \mathrm{10)}$. Finally, the question of renewal needs to be integrated into the strategy i.e. the regeneration of equipment, systems, processes, people etc. Clearly, day-to-day activities will dominate the work agenda but allocation of time and resources is essential to ensure continuous or regenerative improvements take place as part of a comprehensive plan. 


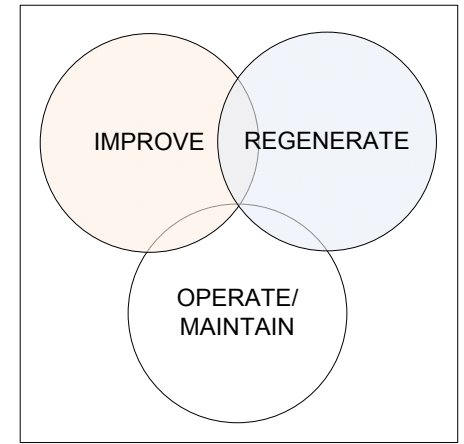

Figure 2. Concept of maintenance work to be covered

When it comes to the detail behind the management of the day-to-day operations there is considerable advice for the practitioner on what needs to be included and how this might be achieved (Kelly, 1997a) (Wireman, 1990). There is also a wealth of advice on how Human Resources (HR) should be managed e.g. (Armstrong, 2011) and many companies have in-house HR support and existing policies and procedures regarding people. With regard to policy decisions these need to take into account 'logistical issues such as; scheduling, spare parts inventory and ordering' (Murthy, 2002 p 293) along with a multitude of other operational and tactical decisions.

\section{Auditing a maintenance strategy}

Another important aspect to consider is the auditing of the maintenance strategy and its "alignment to" and "effect on" manufacturing performance. Is it working? Are the plans in place? Are staff executing the plans? Are the plans reaping the desired results? As discussed in Section 3 it is possible that "contextual factors" can conspire to inhibit the strategy process so it is important to carry out an assessment at the plant to ensure all processes and links are in place and working. Recent research at four case study sites in the North East of England tested and validated a new questionnaire and diagnostic tool which proved capable of measuring the status of strategic processes in manufacturing plants (Robson et al., in press). The series of questions provided in table 1 were taken directly from this questionnaire and can be used for auditing the maintenance strategy process. A small cross-functional team or an independent auditor can be engaged to complete this "maintenance checklist".

Table 1 . A checklist to verify maintenance strategy is in place and working

\section{CHECKLIST}

\section{IS THERE A MAINTENANCE STRATEGY?}

1 Is there a set of documented objectives agreed with manufacturing?

2 Are the maintenance objectives clearly "linked" to the Manufacturing strategy?

3 Was joint consultation used when establishing the objectives between maintenance and manufacturing?

4 Is the contribution that maintenance strategy will make to manufacturing performance established and agreed?

5 Are the maintenance objectives "SMART" i.e. Specific, Measurable, Achievable, Realistic, Timely?

6 Is the maintenance objectives "current state" established?

7 Has a maintenance strategy been formed by comparing the "current state" to the "future state" and assessing how the gap can be bridged?

8 Is there a documented maintenance strategy?

9 Does the maintenance strategy specify what needs doing to meet the maintenance objectives?

10 Have all "key stakeholders" been involved with the development of the "maintenance strategy"?

11 Have Key Performance Indicators (KPI's) been developed for each maintenance objective?

12 Has the maintenance strategy been clearly "communicated" to the whole organization both verbally and visually? 


\section{IS A SET OF PLANS TO IMPLEMENT THE MAINTENANCE STRATEGY AVAILABLE?}

14 Are their documented maintenance action plans?

15 Have owners agreed the action plans?

16 Has adequate resources been allocated to execute the action plans?

17 Can owners provide an update on progress and status of their action plans?

18 DO managers and supervisors hold meetings to review individual or group performance against plans?

IS THE MAINTENANCE TEAM IMPLEMENTING THEIR ACTION PLANS IN THE WORKPLACE?

19 Is there "clear evidence" of the implementation of maintenance action plans on the ground?

20 Are appropriate tools and approaches being used to execute action plans e.g. Team problem solving, DMAIC, PDCA etc.?

21 Are the necessary systems in place to manage maintenance?

22 Are maintenance action plans on target or complete?

23 Does the maintenance team have the necessary skills to complete the action plans?

24 Is their communication of action plans and their progress?

IS THE PROGRESS AGAINST ACTION PLANS

BEING MEASURED AND REVIEWED?

25 Is there a formal system in place to review the progress of maintenance objectives against plan?

27 Is there is a system to control and measure maintenance KPI's?

28 Is there a system to control maintenance KPI's?

29 Is the performance and progress communicated?

IS THE MAINTENANCE GROUP MEETING OR EXCEEDING THEIR TARGETS?

30 Are maintenance action plans on target or complete?

31 Is the maintenance team achieving their objectives?

32 Are KPI's is on target?

\section{Conclusions}

Research has shown that manufacturing companies are not creating maintenance strategies and linking them to their manufacturing and business goals (Robson et al., in press). This paper has proffered a practical guide for maintenance managers to follow. It has covered the formulation and implementation of maintenance strategy in terms of; process, content and context and has recommended that maintenance strategies be holistic and take into account three levels of work; day-to-day, continuous improvement and regenerative. It was acknowledged that the majority of maintenance effort would focus on the day-to-day but maintenance managers should also make sure the necessary resources are allocated to continuous improvement activity. Conclusively, failure to develop and implement a comprehensive maintenance strategy would prejudice machine reliability and therefore negatively affect manufacturing performance in the long term. Conversely, potential benefits for maintenance departments were significant. A coherent maintenance strategy linked to manufacturing and business goals would establish a clear set of objectives for the maintenance function to follow. Moreover, a written and agreed maintenance strategy would raise the strategic profile of the maintenance group within the plant through a measured contribution to the business. The paper also raised the need to secure against contextual factors through the implementation of an auditing system. This would ensure strategic processes and links were in place and working. It was important because empirical research had shown that even when companies thought they had established a maintenance strategy, individual processes were impaired (Robson, 2010). In summary, a maintenance strategy should be formed using a strategic process and during its lifecycle be audited and checked at appropriate intervals to ensure success. 


\section{References}

Ackoff, R. (1981). Creating the corporate future, John Wiley \& Sons,Inc.

Ansoff, I. (1988). Corporate strategy, Penguin.

Armstrong, M. (2011). Armstrong's handbook of strategic human resource management, London, Koganpage.

Barnes, D. (2002). The complexities of the manufacturing strategy formation process in practice. International Journal of Operations, 22, 1090-1111.

Bignell, V., Carter, R., Martin, J., Naughton, J., Peters, G., Spear, R. \& Tait, J. (1984a). The hard systems approach systems model, The Open University Press.

Bignell, V., Carter, R., Martin, J., Naughton, J., Peters, G., Spear, R. \& Tait, J. (1984b). The hard systems approach systems models, The Open University Press.

Certo, S. (1991). Strategic management, McGraw-Hill Inc.

Cholasuke, C., Bhardwa, R. \& Antony, J. (2004). The status of maintenance management in UK manufacturing organisations: results from a pilot survey. Journal of Quality in Maintenance Engineering, 10, 5-15. http://dx.doi.org/10.1108/13552510410526820

Coetzee, J. (1997). Towards a general maintenance model. In: MARTIN, H. H., ed. IFRIM, 1997 Hong Kong. 1-9.

Cross, K., E \& Lynch, R., L. (1989). The SMART way to define and sustain sucess. National Productivity Review, 8, 23-33. http://dx.doi.org/10.1002/npr.4040080105

Genus, A. (2000). The management of change : perspectives and practice, Thompson Business Press.

Geraerds, W. M. J. (1990). The EUT maintenance model. In: MARTIN, H. H., ed. New Developments in Maintenance, 1990 Netherlands. Ernst \& Young Consultants.

Hart, L. (1967). Strategy, Basic books.

Johnson, G. \& Scholes, K. (1993). Exploring corporate strategy, Prentice Hall.

Jonsson, P. (1997). The status of maintenance management in Swedish manufacturing firms. Journal of Quality in Maintenance Engineering, 3, 233-258. http://dx.doi.org/10.1108/13552519710176863

Kelly, A. (1997a). Maintenance organization \& systems - business-centered approach, Athenaeum Press Ltd.

Kelly, A. (1997b). Maintenance strategy - business-centred maintenance, Oxford Reed Educational and Professional Publishing.

Mintzberg, H., Ahlstrand, B. \& Lampel, J. (1998). Strategy safari, The Free Press.

Mintzberg, H. \& Waters, J. A. (1985). Of strategies deliberate and emergent. Strategic Management Journal, 6, 257 272. http://dx.doi.org/10.1002/smj.4250060306

Murthy, D., N.P. (2002). Strategic maintenance management. Journal of Quality in Maintenance Engineering, 8, 287-305. http://dx.doi.org/10.1108/13552510210448504

Pettigrew, A. M. (1987). Context and action in the transformation of the firm Journal of Management Studies 24. http://dx.doi.org/10.1111/j.1467-6486.2012.01054.x

Pinjala, S. K., Pintelon, L. \& Vereecke, A. (2004). An empirical investigation on the relationship between business and maintenance strategies. International Journal of Production Economics. http://dx.doi.org/10.1016/j.ijpe.2004.12.024

Robson, K. (2010). An investigation into the impact on manufacturing performance of the linkage between maintenance and manufacturing strategy. Unpublished $\mathrm{PhD}$ thesis, University of Sunderland.

Robson, K., Macintyre, J. \& Trimble, R. in press. Measuring the status and alignment of Maintenance and Manufacturing Strategies - The development of a new model and diagnostic tool. Journal of Quality in Maintenance Engineering.

Skinner, W. (1969). Manufacturing - missing link in corporate strategy. Harvard Business Review, 1-10.

Slack, N., Chambers, S. \& Johnson, R. (2004). Operations management, Prentice Hall.

Slack, N., Chambers, S. \& Johnson, R. (2007). Operations management, Prentice Hall.

Tsang, A., Jardine, H. \& Kolodny, H. (1999). Measuring maintenance performance: a holistic approach. International 
Journal of Operations \& Production Management, 19, 691-715. http://dx.doi.org/10.1108/01443579910271674

Tsang, A. H. C. (1998). A strategic approach to managing maintenance performance. Journal of Quality in Maintenance Engineering, 4, 87-94. http://dx.doi.org/10.1108/13552519810213581

Voss, C., A. (1992). Manufacturing strategy - process and content, Chapman \& Hall.

Willmott, P. (1994). TPM's place in the quality scene. Quality World, 762-5..

Wireman, T. (1990). World class maintenance management, New York, Industrial Press Inc.

Note 1. The term 'maintenance strategy' can often be confused because authors use it in different contexts. For example, it can describe a tactical approach to maintain a machine e.g. planned maintenance, preventative maintenance, or condition-based maintenance. When used in this paper a maintenance strategy is a "holistically-conceived, written document that records and defines the objectives and policies that will be adopted by the maintenance function". 